MacLennan, A. P. (1956). J. gen. Microbiol. 14, 134-142

\title{
The Production of Capsules, Hyaluronic Acid and Hyaluronidase by Group A and Group C Streptococci
}

\author{
By A. P. MAcLENNAN* \\ Lister Institute of Preventive Medicine, Elstree, Hertfordshire
}

SUMMARY: Some capsulated group A and group C streptococci were found to produce both hyaluronic acid and hyaluronidase during active growth; thus confirming and extending the work of Pike (1948b). In a group C strain, $\mathbf{L M}$, the free hyaluronic acid in liquid culture represents an excess of synthesis over destruction, the balance being influenced by the aeration of the culture. Within the limits examined the degree of aeration did not, however, influence hyaluronidase or hyaluronic acid production by strains producing either the enzyme or its substrate exclusively. A non-capsulated, hyaluronidase producing mutant of strain LM was isolated but capsulated cells, free from this variant, also produced the enzyme. Evidence is presented that the spreading activity of strain LM preparations in rabbit dermis is due to hyaluronidase rather than to capsular material as suggested by Pradhan (1937).

McClean (1941) showed that some strains of streptococci develop capsules in young cultures, whereas others produce hyaluronidase and are not capsulated. Further studies (Crowley, 1944; Pike, 1948a; Russell \& Sherwood, 1949; Murray \& Pearce, 1949) in which a variety of hyaluronidase assay methods were used appeared to establish the fact that streptococci can be classified into strains producing both capsules and hyaluronic acid, those producing hyaluronidase and those producing neither the enzyme nor the acid. Pike $(1948 b)$, however, found that seven of ten capsulated, hyaluronic acid producing, group A strains form a filterable, thermolabile agent which destroys the hyaluronic acid in ageing cultures. More recently, Faber \& Rosendal (1954) have described a fall in hyaluronic acid concentration in ageing cultures of 35 of $\mathbf{4 7}$ group A strains that produce the polysaccharide, the other 12 strains showing no fall in concentration. There is little direct evidence that the slow destruction of hyaluronic acid by cultures of some group A strains is due to a hyalurondase beyond the fact that the destructive agent is thermolabile and filterable. It is justifiable, however, to refer here to the destructive agent as hyaluronidase since in another paper (MacLennan, 1956) the isolation and characterization of an enzyme resembling other streptococcal hyaluronidases from cultures of a hyaluronic acid-producing group $\mathrm{C}$ streptococcus is described. The object of the present work was to examine in more detail the relationships of capsulation, hyaluronic acid and hyaluronidase production in some group A and group C streptococci at all stages of growth.

\footnotetext{
* Present address: Microbiological Research Department, Ministry of Supply, Porton, near Salisbury, Wilts.
} 


\section{MATERIALS AND METHODS}

Source of streptococci. Two capsulated, hyaluronic acid-producing, group A strains, A 118 (Griffith's type 19) and A 111 (Griffith's type 18), were gifts from Dr R. Pike who reported (Pike, 1948b) that A118 but not A111 produced hyaluronidase. A third group A strain, type 1 (NCTC 8198) was also examined. The three group C strains were LG (NCTC 6178), C 7 (NCTC 4540), known to be a hyaluronidase producer, and strain LM (NCTC 6176), which was described by Pradhan (1937) as having spreading factor activity in young serum broth cultures.

Cultivation of streptococci. Cultures were grown in a $2.5 \%$ Evans' peptone, $10 \%$ horse serum, $1 \%$ glucose, horse meat infusion broth, hereafter PSB, from inocula of once-washed saline suspensions of overnight growth in the same medium. Each $100 \mathrm{ml}$. of medium was seeded with organisms from $10 \mathrm{ml}$. of overnight growth in the same medium suspended in $1 \mathrm{ml}$. saline. Cultures were kept at $\mathrm{pH} 7 \cdot 0-7 \cdot 6$ during growth by the addition of $10 \%$ sodium hydroxide. A replicate culture containing $0.002 \%$ phenol red was used as a guide to neutralization since the presence of phenol red in experimental cultures led to high blank values in the colorimetric estimation of hyaluronic acid.

For aerobic and anaerobic cultivation respectively, oxygen or nitrogen gas, each containing $5 \%$ carbon dioxide, was bubbled into cultures through perforated rubber tube spargers. Silicone Antifoam A was added to prevent foaming.

Measurement of growoth. Bacterial $\mathrm{N}$ was measured on washed cells by the micro-Kjeldahl method.

Capsulation. A loopful of culture and a loopful of cobalt blue ink (Uno waterproof ink) were mixed on a grease-free slide, smeared and then dried without heating. After staining with 1/6 Löffler's methylene blue for $3 \mathrm{~min}$. and washing in water the preparation was dried without heating. Dr Nuala Crowley (personal communication) suggested the use of 'Uno' ink which gives a more uniform background than other inks.

Hyaluronic acid. The turbidimetric method described by Pike (1946) was used with Allen and Hanburys hyaluronic acid as a standard. Turbidities were measured on the Evans' Electroselenium Co. Ltd. (EEL) colorimeter using a blue filter, No. 622 .

Hyaluronidase. This was estimated by the mucin clot prevention (M.c.P.) test as described by McClean (1943). For the test hyaluronic acid of high viscosity was prepared from human umbilical cords by the method of McClean (1943). To detect small quantities of hyaluronidase the incubation period of the test was increased from $20 \mathrm{~min}$. to $24 \mathrm{hr}$. and thiomersalate was added to the enzyme substrate reaction mixture to a concentration of $1 / 10,000$.

Small amounts of hyaluronidase in culture supernatants were also detected by a method differing only in detail from that of Pike (1948a). Two ml. of culture supernatant and $2 \mathrm{ml}$. of a solution of $40 \mathrm{mg}$. hyaluronic acid (Allen and Hanburys)/ $/ 100 \mathrm{ml}$. culture medium were mixed and incubated at $37^{\circ}$ for a period which was varied according to the activity of the enzyme present, 
but which was of course the same for any experiment in which activities were being compared. The mixture was held at $\mathrm{pH} 7 \cdot 3-7 \cdot 5$ and contained $1 / 10,000$ thiomersalate. The hyaluronic acid remaining after incubation was determined turbidimetrically by Pike's method (1946). Enzyme activity was expressed as $\mathrm{mg}$. hyaluronic acid destroyed/100 $\mathrm{ml}$. of reaction mixture.

\section{RESULTS}

\section{A survey of strains}

Figure 1 records the growth and hyaluronic acid production of 3 group A and 3 group $\mathrm{C}$ strains after one passage through mice. Hyaluronidase production and capsulation were also measured at hourly intervals. In order to detect small amounts of hyaluronidase the incubation period of the M.C.P. test was
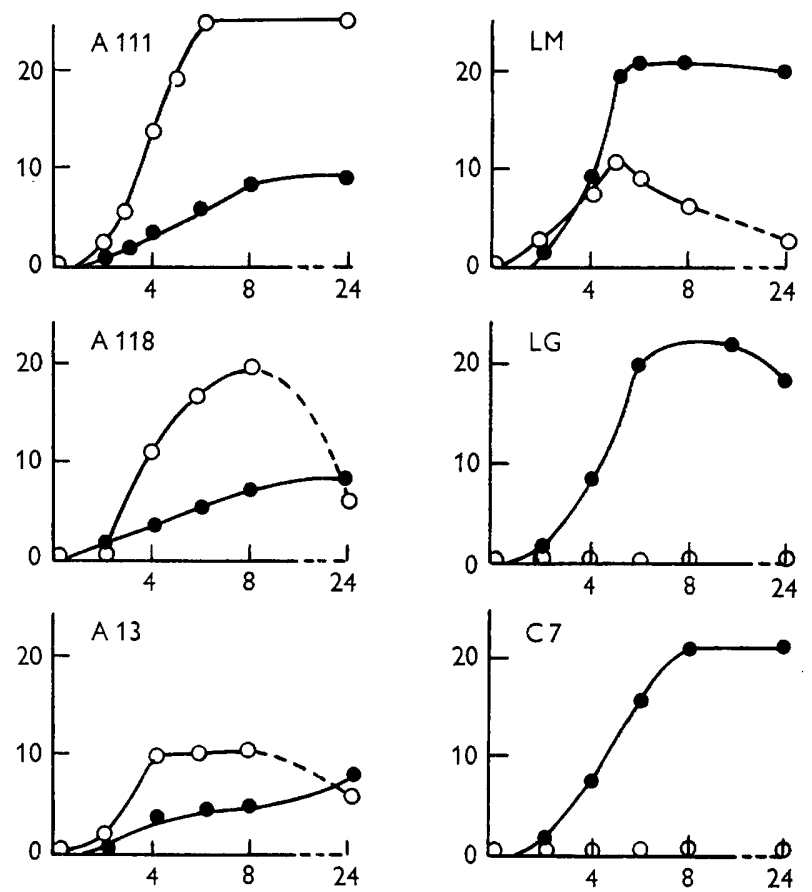

Fig. 1. The growth and hyaluronic acid production of streptococci. Ordinates: mg. hyaluronic acid/100 ml. culture $(\mathrm{O}-\mathrm{O})$ and $\mathrm{mg}$. bact. N/100 ml. culture $(\bullet-\bullet)$. Abscissae: age of culture (hr.).

increased to $24 \mathrm{hr}$. Group $\mathrm{C}$ strains grew more regularly and more abundantly than did group A strains. Two of the group $\mathrm{C}$ strains, LG and $\mathrm{C} \mathrm{7}$, were without capsules at all stages of growth and failed to produce hyaluronic acid; LG produced no detectable hyaluronidase, but strain $\mathrm{C} 7$ produced very high titres throughout growth.

Strain LM and the three group A strains, on the other hand, produced capsules and hyaluronic acid. Production was associated with the phase of 
active growth as reported by Seastone (1939), Morison (1940) and others. In all four strains the capsules were lost towards the close of the log phase and in three, A 13, A 118 and LM, there was a corresponding fall in the concentration of hyaluronic acid in the cultures. This fall in ageing cultures of A13, A118 and LM and the persistence of the polysaccharide in those of A 111 confirms and extends the observations of Pike (1948b). Strain LM is the first group C strain to have been shown to produce both hyaluronic acid and hyaluronidase. Since this work was begun Faber \& Rosendal (1954) have reported hyaluronidase formation by hyaluronic acid producing strains of the three group A serological types 1, 19 and 18 represented here by A 13, A118 and A111 respectively.

Because the M.c.P. test had failed to detect hyaluronidase in those cultures in which hyaluronic acid had been destroyed it seemed probable that the failure of earlier workers (McClean, 1941; Crowley, 1944) to demonstrate enzyme activity in cultures of capsulated strains by the M.c.P. test using a much shorter incubation period was due to its relative insensitivity. To verify this a comparison of the M.c.P. test $(20 \mathrm{~min}$. incubation) and the turbidimetric method ( $16 \mathrm{hr}$. incubation) described above was made. The enzyme activity of a strain LM culture supernatant free from hyaluronic acid was compared turbidimetrically with that of a series of dilutions of the supernatant of the hyaluronidase producing strain $\mathrm{C} 7$ containing 1 M.C.P. unit $/ \mathrm{ml}$. and less. The destruction of hyaluronic acid by $\mathrm{C} 7$ dilutions containing only $0 \cdot 04-0 \cdot 2$ M.c.P. units was equal to that of the undiluted LM supernatant.

Strain LM differed from strain A 111 in the small amount of hyaluronic acid present despite good capsulation. It was thought that this might be due to a rapid enzymic breakdown of hyaluronic acid liberated from the capsule by this strain. Duplicate cultures of strain LM were therefore sampled at intervals during growth. The samples were centrifuged and each supernatant sterilized by $1 / 10,000$ thiomersalate, duplicate portions being then stored for $16 \mathrm{hr}$. at $2^{\circ}$ and $37^{\circ}$ respectively. Residual hyaluronic acid was then determined. The complete disappearance of hyaluronic acid from all supernatants stored at $37^{\circ}$ shows clearly that hyaluronidase is liberated into the culture medium at an early stage of growth (Table $\mathbf{1}$ ). This observation was consistently reproduced; no culture supernatant of strain LM was ever found to contain hyaluronic acid that was not destroyed by incubation at $37^{\circ}$ after sterilization. The curve in Fig. 2 represents the polysaccharide content of a growing strain LM culture and the three curves arising from this show the fall in concentration that occurred in $4 \frac{1}{4}, 6$ and $7 \frac{1}{2} \mathrm{hr}$. sterilized samples of culture supernatants when incubated at $37^{\circ}$. During growth between $4 \frac{1}{4}$ and $6 \mathrm{hr}$. the concentration of hyaluronic acid rose by $7 \mathrm{mg} . / 100 \mathrm{ml}$. and yet if growth were prevented during this period there was a fall of $2.5 \mathrm{mg}$./100 ml. Moreover, in the growing culture the hyaluronidase was acting on a constantly increasing concentration of polysaccharide, whereas under bacteriostatic conditions the substrate concentration fell steadily. From what is known of enzyme kinetics it is likely that the loss of hyaluronic acid during $1 \frac{3}{4} \mathrm{hr}$. growth was greater than $2.5 \mathrm{mg}$. $/ 100 \mathrm{ml}$. The results of these two experiments show clearly that the 
amount of hyaluronic acid found in a strain LM culture represents a balance of synthesis and destruction. As will be shown later the presence of the enzyme in young cultures of strain LM is of interest in the light of Pradhan's (1937) report that young cultures of this strain in the capsulated phase had spreading factor activity in rabbit dermis; he attributed this activity to the capsular substance itself.

Table 1. The time of appearance of hyaluronidase in cultures of strain $\mathbf{L M}$

Mg. hyaluronic acid/100 $\mathrm{ml}$. of culture.

$\begin{array}{ccccc}\begin{array}{c}\text { Age } \\ \text { of culture } \\ \text { (hr.) }\end{array} & \overbrace{1} & 2 & \overbrace{1} & 37^{\circ} \\ 2 & 0 & 0 & 0 & 0 \\ 4 & 5 \cdot 5 & 4 \cdot 3 & 0 & 0 \\ 5 & 10 & 8 \cdot 7 & 0 & 0 \\ 6 & 6 \cdot 3 & 5 \cdot 2 & 0 & 0 \\ 7 & 6 \cdot 2 & 5 \cdot 2 & 0 & 0 \\ 8 & 5 \cdot 7 & - & 0 & 0 \\ 24 & 0 & 0 & 0 & 0\end{array}$

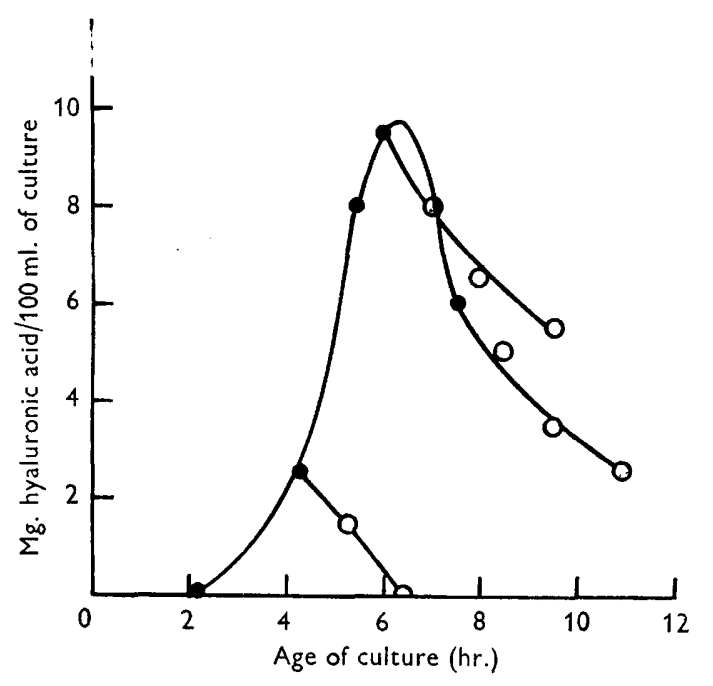

Fig. 2. The rates of accumulation and destruction of hyaluronic acid in a culture of strain LM. Accumulation during growth (-)); destruction in the absence of growth (O-O).

\section{The influence of aeration}

It was hoped that an interference with metabolism, such as might be brought about by growth under widely different conditions of aeration, would throw light on the balance of hyaluronic acid synthesis and destruction. The production of hyaluronic acid by strain A 111, however, was not influenced by shake or static cultivation (Table 2), despite a prolongation of exponential 
growth in shake culture. In completely anaerobic culture growth was slow and poor but $4.9 \mathrm{mg}$. polysaccharide/mg. bacterial $\mathrm{N}$ was present after $24 \mathrm{hr}$. growth compared with $5 \cdot 2 \mathrm{mg}$. for a shake culture of strain A 111 at an equivalent stage

Table 2. The production of hyaluronic acid by strain $A 111$ in shake and static culture

\begin{tabular}{|c|c|c|c|c|}
\hline \multirow{3}{*}{$\begin{array}{c}\text { Age of } \\
\text { culture } \\
\text { (hr.) }\end{array}$} & \multicolumn{4}{|c|}{ Mg. hyaluronic acid $/ 100 \mathrm{mI}$. of culture } \\
\hline & \multicolumn{2}{|c|}{ Static } & \multicolumn{2}{|c|}{ Shake } \\
\hline & 1 & 2 & 1 & 2 \\
\hline 0 & 0 & 0 & 0 & $\mathbf{0}$ \\
\hline 1 & $\mathbf{2 \cdot 5}$ & $2 \cdot 5$ & 3 & 2 \\
\hline 2 & $7 \cdot 3$ & $7 \cdot 3$ & $6 \cdot 3$ & $5 \cdot 7$ \\
\hline 3 & 18 & 17 & $15 \cdot 5$ & $13 \cdot 5$ \\
\hline 4 & 34 & 33 & 30 & 26 \\
\hline 5 & 44 & 44 & 41 & 38 \\
\hline 6 & 54 & 52 & 56 & 54 \\
\hline 7 & 66 & 61 & - & 72 \\
\hline 8 & 72 & 72 & 80 & 98 \\
\hline 24 & 88 & 88 & 80 & 98 \\
\hline
\end{tabular}

of growth in terms of bacterial N. Furthermore, the production of hyaluronidase by the non-capsulated strain $\mathrm{C} 7$ at all stages of growth was not greatly influenced by extreme aerobiosis or anaerobiosis as judged by rough titrations of enzyme by the M.C.P. method (Table 3). The higher titres in young anaerobic culture are probably due to the shorter growth lag. The degree of aeration,

Table 3. The production of hyaluronidase by strain $\mathrm{Cr}$ in aerobic and anaerobic culture

$\begin{array}{crrrr}\begin{array}{c}\text { Age of } \\ \begin{array}{c}\text { culture } \\ (\text { hr. })\end{array}\end{array} & \overbrace{1}^{2} & 2 & \overbrace{1} & \text { Aerobic } \\ 2 & <12 & <12 & <12 & 2 \\ 3 & 50 & 25 & 25 & <12 \\ 4 & 200 & 200 & 100 & 100 \\ 5 & 400 & 400 & 200 & 400 \\ 6 & 400 & 200 & 200 & 400 \\ 7 & 400 & 400 & 400 & 400 \\ 24 & 1600 & \text { Anaerobic } & 800 & 800\end{array}$

however, markedly influenced the balance of hyaluronic acid synthesis and destruction by strain LM (Table 4). As with strain $\mathrm{Cr}$ there was a shorter growth lag in anaerobic than in aerobic culture, but this in itself could not account for the faster rate of hyaluronic acid disappearance anaerobically since the difference in the rates of this disappearance was much greater than the differences in the growth lag. Anaerobiosis might select mutants with enhanced hyaluronidase production, as reported by Sallmann (1951) for group A and group C strains whose capsulation was not examined, or reduce the lag in hyaluronidase synthesis. Rogers (1954) has shown that 
such a lag, differing from the ordinary growth lag, exists for constitutive hyaluronidase synthesis by some staphylococci. Faber \& Rosendal (1954) report a more rapid production of hyaluronidase by group A strains under anaerobic conditions but do not state whether growth rate is also increased. It is also possible that hyaluronic acid synthesis itself in strain LM, unlike that in A 111, is influenced by aeration and that enzyme production is unaffected.

Table 4. The production of hyaluronic acid and capsules by strain LM in aerobic and anaerobic culture

$\begin{gathered}\text { Age of } \\ \text { culture } \\ \text { (hr.) }\end{gathered}$
2
3
$3 \frac{1}{2}$
4
$4 \frac{1}{2}$
5
6
7
24

$\overbrace{\text { Anaerobic }}^{\text {Capsulation }} \begin{array}{cc}\text { Aerobic } \\ + & + \\ + & + \\ + & + \\ + & + \\ + & + \\ + & + \\ 0 & + \\ 0 & + \\ 0 & 0\end{array}$

Mg. hyaluronic acid/100 ml. culture

$\begin{array}{cc} & \\ \text { Anaerobic } & \text { Aerobic } \\ 3 & 3 \\ 8 & 13 \\ 10 & 21 \\ 13 & 28 \\ 5 & 28 \\ 0 & 26 \\ 0 & 22 \\ 0 & 2 \\ 0 & 0\end{array}$

Measurements of hyaluronidase activity in aerobic and anaerobic cultures of strain LM using the turbidimetric method showed that enzyme activity reaches a maximum towards the end of the log phase of growth, whether aerobic or anaerobic, and then falls quite sharply. Cultures at $24 \mathrm{hr}$. were much less active than at $6-8 \mathrm{hr}$. Pike $(1948 \mathrm{a})$ reported an inexplicable fall in hyaluronidase activity of ageing cultures of some non-capsulated group A and group $\mathrm{C}$ streptococci which may have been similar in nature to that described here. In Pike's work, as in this, the fall occurred at neutral pH. The loss of activity is due to the extreme thermolability of strain LM enzyme (MacLennan, 1956).

\section{The spreading activity of strain LM cultures}

The spreading factor activity in young strain LM culture supernatants, attributed by Pradhan (1937) to capsular material, might be caused by small amounts of hyaluronidase present. Streptococcal hyaluronidase is a potent spreading factor (McClean, 1941) and, moreover, isolated group C capsular hyaluronic acid has no spreading activity (Seastone, 1939). Furthermore, the fall of spreading activity in old cultures noted by Pradhan and attributed by him to capsule loss is equally explicable by the inactivation of hyaluronidase reported above. To exclude capsular material as the cause of spreading activity it is sufficient to demonstrate this activity in a strain LM culture free from capsules and hyaluronic acid, since the enzyme has already been demonstrated (Table 1) in the younger, capsulated cultures shown by Pradhan to possess spreading activity.

Strain LM was grown in PSB in which serum was replaced by distilled water; the absence of serum increases hyaluronidase activity (Pike, 1948a; 
MacLennan, 1956). At $8 \mathrm{hr}$. enzyme activity was maximal, falling to a low value at $24 \mathrm{hr}$. Hyaluronic acid could not be detected turbidimetrically at $8 \mathrm{hr}$. and capsules were absent. The $8 \mathrm{hr}$. culture was centrifuged and the supernatant filtered through a bacterial, sintered glass filter. A portion of the filtrate was heated at $56^{\circ}$ for $1 \mathrm{hr}$. to serve as a control. After the addition of trypan blue (vital) to a concentration of $1 \%, 0.25 \mathrm{ml}$. vol. of the heated and unheated filtrates were injected intradermally into white rabbits. Samples of heated and unheated medium were injected as additional controls. Each preparation was injected into four rabbits at two sites and heated and unheated, but otherwise homologous, preparations were injected into comparable sites on the opposite flanks of each rabbit. It was noted that only the blebs produced by the unheated culture supernatant flattened out quickly. After $1 \mathrm{hr}$. the rabbits were flayed and the dyed area measured by tracing on to graph paper. Table 5 shows that the $8 \mathrm{hr}$. culture had a slight but definite, thermolabile, spreading activity. Since the culture was not capsulated and hyaluronic acid was absent this activity can be attributed to the small amount of hyaluronidase present.

Table 5. The spreading factor activity of a strain LM $8 \mathrm{hr}$. culture supernatant in rabbit dermis

\begin{tabular}{|c|c|c|c|c|c|c|}
\hline \multirow[b]{2}{*}{$\begin{array}{c}\text { Rabbit } \\
\text { no. }\end{array}$} & \multicolumn{5}{|c|}{ Area of dye spread (sq.cm.). } & \multirow[b]{2}{*}{ Difference } \\
\hline & $\begin{array}{l}\text { Culture } \\
\text { medium }\end{array}$ & $\begin{array}{l}\text { Heated } \\
\text { culture } \\
\text { medium }\end{array}$ & Difference & $\begin{array}{c}8 \mathrm{hr} . \\
\text { culture } \\
\text { supernatant }\end{array}$ & $\begin{array}{c}\text { Heated } \\
\text { culture } \\
\text { supernatant }\end{array}$ & \\
\hline 1 & $\begin{array}{r}10 \cdot 8 \\
9 \cdot 0\end{array}$ & $\begin{array}{l}9 \cdot 0 \\
9 \cdot 2\end{array}$ & $\begin{array}{r}1 \cdot 8 \\
-0 \cdot 2\end{array}$ & $\begin{array}{l}17 \cdot 4 \\
14 \cdot 4\end{array}$ & $\begin{array}{r}15 \cdot 0 \\
9 \cdot 6\end{array}$ & $\begin{array}{l}2 \cdot 4 \\
4 \cdot 8\end{array}$ \\
\hline 2 & $\begin{array}{l}10 \cdot 2 \\
12 \cdot 2\end{array}$ & $\begin{array}{r}9 \cdot 6 \\
10 \cdot 4\end{array}$ & $\begin{array}{l}0.6 \\
1 \cdot 8\end{array}$ & $\begin{array}{l}14 \cdot 8 \\
18 \cdot 6\end{array}$ & $\begin{array}{r}9 \cdot 0 \\
10 \cdot 2\end{array}$ & $\begin{array}{l}5 \cdot 8 \\
8 \cdot 4\end{array}$ \\
\hline 3 & $\begin{array}{l}13 \cdot 2 \\
11 \cdot 8\end{array}$ & $\begin{array}{l}12 \cdot 4 \\
11 \cdot 6\end{array}$ & $\begin{array}{l}0 \cdot 8 \\
0 \cdot 2\end{array}$ & $\begin{array}{l}19 \cdot 4 \\
20 \cdot 8\end{array}$ & $\begin{array}{l}15 \cdot 8 \\
12 \cdot 2\end{array}$ & $\begin{array}{l}3 \cdot 6 \\
8 \cdot 6\end{array}$ \\
\hline 4 & $\begin{array}{l}14 \cdot 8 \\
11 \cdot 0\end{array}$ & $\begin{array}{l}10 \cdot 0 \\
12 \cdot 6\end{array}$ & $\begin{array}{r}4 \cdot 8 \\
-1.6\end{array}$ & $\begin{array}{l}14 \cdot 8 \\
16 \cdot 2\end{array}$ & $\begin{array}{l}11 \cdot 8 \\
10 \cdot 2\end{array}$ & $\begin{array}{l}3 \cdot 0 \\
6 \cdot 0\end{array}$ \\
\hline
\end{tabular}

\section{Mode of hyaluronidase production by strain LM}

The production of hyaluronidase by strain LM might be due to a substrate induced (adaptive) enzyme synthesis or to the selection of hyaluronidase producing mutants. That variants occur is evident from the observation that strain LM, as revived from an NCTC stock culture on to moist, $20 \%$ horse serum, $1 \%$ glucose agar plates, yields two distinct colony types, mucoid and non-mucoid, containing respectively capsulated and non-capsulated cells. The two variants bred true on successive subculture. Grown in PSB with continual neutralization, capsulated organisms were produced only by the mucoid variant. Hyaluronidase was, however, produced by both variants from early growth onwards. Enzyme titres were similar, although the enzyme was formed rather later by the non-capsulated variant. On plating $24 \mathrm{hr}$. cultures mucoid colonies alone were obtained from the mucoid cultures and only non-mucoid colonies from the non-mucoid cultures. Fifty mucoid colonies were grown 
separately in PSB; hyaluronic acid was absent from all cultures after $24 \mathrm{hr}$. growth.

It appears that capsulated cells are able to form hyaluronidase and that, although non-capsulated cells also produce the enzyme, the destruction of hyaluronic acid in cultures of the mucoid form is not due to the selection of non-capsulated variants. There was no evidence that some capsulated cells were unable to produce hyaluronidase. In view of the similar degree of enzyme production by capsulated and non-capsulated organisms it appears that the non-capsulated state is due to a loss of ability to synthesize capsular material rather than to the suppression of the capsule by enhanced enzyme activity. It also appears that enzyme formation is not stimulated by the presence of its substrate since were this so the capsulated organism would be expected to produce hyaluronidase in relatively large amounts in response to the presence of a high local concentration of hyaluronic acid in the capsule.

I wish to thank Dr D. MeClean for his guidance and encouragement in this work which formed part of a Ph.D. thesis submitted to the University of London, 1954.

\section{REFERENCES}

Crowley, N. (1944). Hyaluronidase production by haemolytic streptococei of human origin. J. Path. Bact. 56, 27.

Faber, V.\& Rosendal, K. (1954). Streptococcal hyaluronidase. II. Studies on the production of hyaluronic acid and hyaluronidase by representatives of all types of hemolytic streptococci belonging to group A. Acta path. microbiol. scand. 35, 159.

MCClean, D. (1941). The capsulation of streptococci and its relation to diffusion factor (hyaluronidase). J. Path. Bact. 53, 13.

McClean, D. (1943). Studies on diffusing factors. 2. Methods of assay of hyaluronidase and their correlation with skin diffusing activity. Biochem. J. 37, 169.

MacLennan, A. P. (1956). The isolation and characterization of a hyaluronidase produced by a capsulated strain of group C streptococcus. J. gen. Microbiol. 14, 143.

Morison, J. E. (1940). Capsulation of haemolytic streptococei in relation to colony formation. J. Path. Bact. 51, 401.

Murray, R. G. E. \& Pearce, R. H. (1949). The detection and assay of hyaluronidase by means of mucoid streptococci. Canad. J. Res. E, 27, 254.

Pike, R. M. (1946). A study of group A streptococci from healthy carriers with particular reference to mucoid polysaccharide production. J. infect. Dis. 79, 148.

Pike, R. M. (1948 a). Streptococcal hyaluronic acid and hyaluronidase. I. Hyaluronidase activity of non-capsulated group A streptococci. J. infect. Dis. 83, 1.

PIKE, R. M. (1948b). Streptococcal hyaluronic acid and hyaluronidase. II. Production and subsequent destruction of hyaluronic acid by certain strains of group $\mathrm{A}$ streptococci. J. infect. Dis. 83, 12.

Pradhan, M. G. (1937). An investigation of the invasiveness of a strain of Streptococcus haemolyticus. Brit. J. exp. Path. 18, 90.

RogERs, H. J. (1954). The rate of formation of hyaluronidase, coagulase and total extracellular protein by strains of Staphylococcus aureus. J. gen. Microbiol. 10, 209.

Russeld, B. E. \& Sherwood, N. P. (1949). Studies on streptococci. II. The role of hyaluronidase in experimental streptococcal infection. $J$. infect. Dis. 84, 81.

SallmanN, B. (1951). The process of hyaluronidase formation by haemolytic streptococi. J. Bact. 62, 741 .

Seastone, C. V. (1939). The virulence of group C hemolytic streptococci of animal origin. J. exp. Med. 70, 361.

(Received 8 August 1955) 